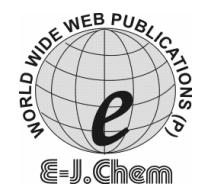

http://www.e-journals.net
ISSN: 0973-4945; CODEN ECJHAO

E-Journal of Chemistry

2010, 7(4), 1477-1483

\title{
Synthesis of Various Polyaniline / Clay Nanocomposites Derived from Aniline and Substituted Aniline Derivatives by Mechanochemical Intercalation Method
}

\author{
N. KALAIVASAN and S. SYED SHAFI* \\ Thanthai Periyar Government Institute of Technology, \\ Vellore, Tamailnadu, 632 002, India. \\ *P.G. \& Research, Department of Chemistry, \\ Islamiah College, Vaniyambadi, Tamailnadu, 635 752, India. \\ nkvasan78@gmail.com
}

Received 10 October 2009; Accepted 5 December 2009

\begin{abstract}
Polyaniline clay nanocomposite can be prepared by mechanochemical method in which intercalation of anilinium ion into the clay lattices accomplished by mechanical grinding of sodium montmorillonite (Na+MMT) in presence of anilinium hydrochloride at room temperature using mortar \& pestle for about $30 \mathrm{~min}$ and subsequent grinding with oxidizing agent, ammonium peroxysulfate. The appearance of green colour indicates the formation of polyaniline/clay nanocomposite (PANI/Clay). Similarly aniline derivatives like $o$-toludine and $o$-anisidine in the form of $\mathrm{HCl}$ salt can form intercalation into the clay lattices. The intercalated aniline derivatives were ground mechanically in presence of oxidizing agent ammonium peroxysulfate lead to formation of substituted polyaniline/ clay nanocomposites. The characteristics of various polyaniline-clay nanocomposites were investigated using UV-Visible, FT-IR, cyclic voltammetry studies.
\end{abstract}

Keywords: Polyaniline, Substituted polyaniline, Mechanochemical method, Clay nanocomposite.

\section{Introduction}

Polyaniline is one of the most studied conducting polymers because of their high stability, enhanced conductivity and processability. They are widely used in different areas of research including electronics, solar cells, batteries, electromagnetic shielding devices, anticorrosive coating and sensors ${ }^{2,3}$. It has been proved that the bulk electronic properties of PANI can be modified by templates assisted synthesis of polyaniline/clay nanocomposites ${ }^{4,5}$. 
A multi-layer assembly of clay plates in presence of conjugate polymer system can be used to regulate the tunneling of charge carriers and the electron transfer properties ${ }^{6,7}$. Polyaniline/montmorillonite clay nanocomposites have been synthesized by various methods. Mostly, polyaniline/clay nanocomposite can be synthesized by intercalation of monomer at elevated temperature followed by oxidative polymerisation of aniline in presence of oxidant like $\left(\mathrm{NH}_{4}\right)_{2} \mathrm{~S}_{2} \mathrm{O}_{8}{ }^{8,9}$. Recently, a mechanochemical technique has been proposed for the synthesis of polymer/clay nanocomposite in which the monomer intercalation and polymerization can be accomplished by mechanical grinding in mortar and a pestle $\mathrm{e}^{10-12}$. This technique is considered to be a green chemistry way of production of bulk polyaniline/clay nanocomposites. In a similar way, a ball mill grinding technique also proposed for the synthesis of polymer nanocomposites ${ }^{13}$. In the present investigation, we have synthesised polyaniline clay nanocomposites by mechanochemical method using aniline and its derivatives. A detailed investigation has been carried out for the intercalation of aniline and its derivatives using various analytical techniques. The structural characteristics of polyaniline/clay nanocomposites were studied by optical and electrochemical techniques.

\section{Experimental}

Aniline, $o$-toludine, $o$-anisidine and $\left(\mathrm{NH}_{4}\right)_{2} \mathrm{~S}_{2} \mathrm{O}_{8}$ (AR grade) were obtained from Merck, India. Aniline was distilled under reduced pressure and stored at $5{ }^{\circ} \mathrm{C}$. Clay sample was obtained from Aldrich, USA. All other chemicals were purchased from commercial sources.

\section{Instrumentation}

\section{$U V$-visible spectrophotometry}

All absorption spectra were collected by using shimadzu, UV-3100, Japan with a path length $1 \mathrm{~cm}^{2}$. The powdered samples were dispersed in $N$-methyl pyrrolidone (NMP) for the UV-Visible studies.

\section{FT-IR}

FT-IR spectra were recorded by Perkin - Elmer spectrometer (FT-1K, 16PC) using $\mathrm{KBr}$ Pallets. All spectra were recorded against the background spectrum of $\mathrm{KBr}$.

\section{Cyclic voltammetric studies}

Cyclic voltammogram were recorded using CHI instruments, USA (Model.616A). A threeelectrode cell step up with a single compartment arranges was used. A gold electrode with $2 \mathrm{~mm}$ diameter rod was used as working electrode and platinum foil and Ag wire were acted as counter electrode and reference electrode respectively. The powdered polyaniline samples were dispersed in NMP solution and then applied to electrode surface for the electrochemical studies.

\section{Preparation of polyaniline/clay nanocomposite}

The PANI/clay nanocomposite was prepared in the following way. A mixture of sodium montmorillonite (Na+MMT) $1.0 \mathrm{~g}$ was suspended with a few drops of water and a required amount of aniline- $\mathrm{HCl}$ was added and the reaction mixture was mechanically ground in a mortar \& pestle at room temperature for $10 \mathrm{~min}$. The grinding processes was continued further followed by the addition of a sufficient amount of $\left(\mathrm{NH}_{4}\right)_{2} \mathrm{~S}_{2} \mathrm{O}_{8}$ [ the molar of $\left(\mathrm{NH}_{4}\right)_{2} \mathrm{~S}_{2} \mathrm{O}_{8}$ to aniline $\mathrm{HCl}$ was (1.5)]. The reaction mixture was allowed to stand for $72 \mathrm{~h}$ and the appearance of the dark green powder indicates the formation of PANI/clay nanocomposite, which was isolated 
by extensive washing with distilled water and followed by dil. $\mathrm{HCl}$. The final product was dried under vaccum. Similarly, other substituted polyaniline derivatives like poly(o-anisidine) and poly $(o$-toludine $) /$ clay nanocomposites were also prepared. Free stand polyaniline and polyaniline derivatives were synthesized based on reported method ${ }^{14-16}$.

\section{Results and Discussion}

\section{$U V$-visible spectroscopy}

Some of the preliminary studies show that intercalation and amount loading of anilinum ion was measured by UV-visible spectral studies due to UV absorption characteristic of aniline ${ }^{17}$. The UV-visible spectra for intercalated aniline and substituted anilines were recorded using dilute suspension of ANI-MMT in NMP solution. Figure 1 shows the UV-visible absorption spectrum of aniline and derivatives intercalated in to the clay galleries. A sharp UV absorption peaks were observed between 340 and $355 \mathrm{~nm}$ are assigned for the $n-\pi^{*}$ transition of neutral aniline and other aniline derivatives $o$-anisidine and $o$-toludine respectively. The absorption peaks were red shifted for the free anilinium ion and the substituted aniline derivatives. Due to the linear arrangement of aniline ions within clay galleries, the peak was blue shifted. The amount of loading of anilinium ion within clay was measured by UV-visible spectral studies. The amount of loading of anilinium ion within clay was high in the case of mechanochemical encapsulated method when compared with solution based exchange reaction at elevated temperature i.e. at $80{ }^{\circ} \mathrm{C}$. The exchange capacity of aniline ion and its derivatives was further confirmed by XRD analysis. The thickness of the silicate layer is about $0.96 \mathrm{~nm}$ and the interlayer distance (dl) for each intercalation compound is calculated from the corresponding d001 space. The basal spacing of ANI-MMT was $1.48 \mathrm{~nm}$ showing the inter layer spacing by $0.52 \mathrm{~nm}$. The interlayer spacing was determined by subtracting the thickness of an individual of MMT $(0.96 \mathrm{~nm})$.

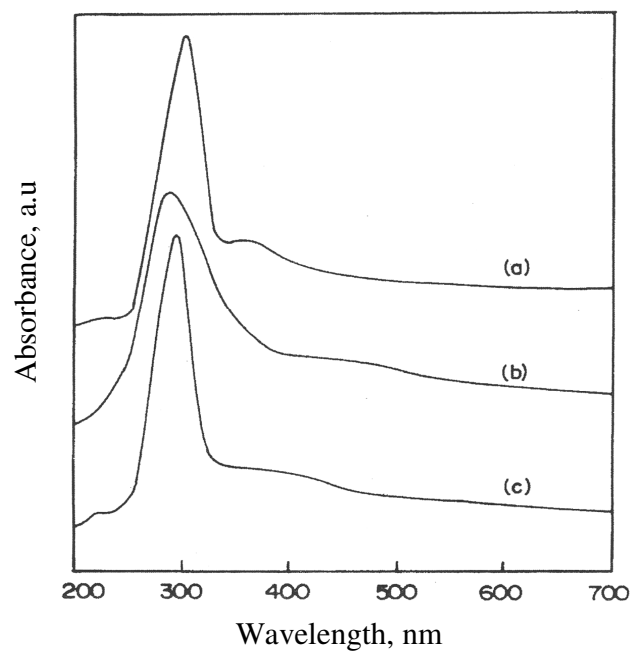

Figure 1. UV-visible spectra of aniline (a), $o$-toluidine (b) and $o$-anisidine (c) intercalated clay

The anilinium ion peak was disappeared after mechanochemical polymerization of aniline-MMT in presence of stoichiometric quantity of oxidizing agent, $\left(\mathrm{NH}_{4}\right)_{2} \mathrm{~S}_{2} \mathrm{O}_{8}$. Two new peaks were observed for the polyaniline/clay nanocomposite, one at $30 \mathrm{~nm}$ and another at $650 \mathrm{~nm}$ and were assigned as $\pi-\pi^{*}$ and localized polaron- $\pi$ transition. Due to the confined arrangement of polymer within the clay lattices, the polaron band is slightly blue shifted. 
Similarly poly $(o$-anisidine $)$ and poly(o-toluidine) polaron peaks are also shifted in the lower wavelengths (Figure 2). The main idea of choosing methyl and methoxy group substituted aniline derivatives because they form a freely soluble and flexible polymer in clay lattices. The physicochemical properties and oxidation potential could be altered. The data were given in the table for the both doped and undoped form of polyaniline within the clay galleries. The UV-visible spectral data were compared for both free standing polyaniline and polyaniline within clay lattices by dispersing in NMP. For comparison UV-Visible spectrum have been run for both polyaniline-clay nanocomposite as prepared and undoped form and emeraldine base form (Figure 3). The undoped form of polyaniline clay nanocomposite was freely soluble in NMP solution then the emeralding salt form.

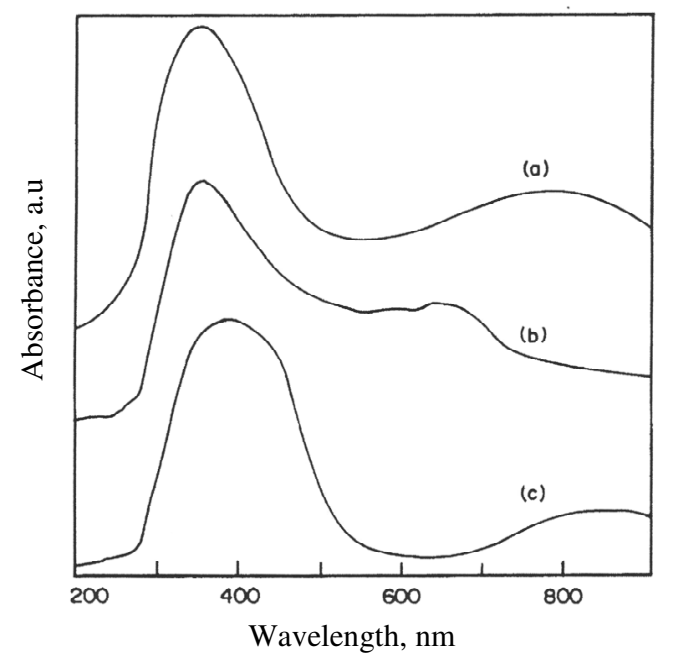

Figure 2. UV-visible spectra of polyaniline (a), poly(o-toluidine) (b) and poly(o-anisidine) (c) as prepared

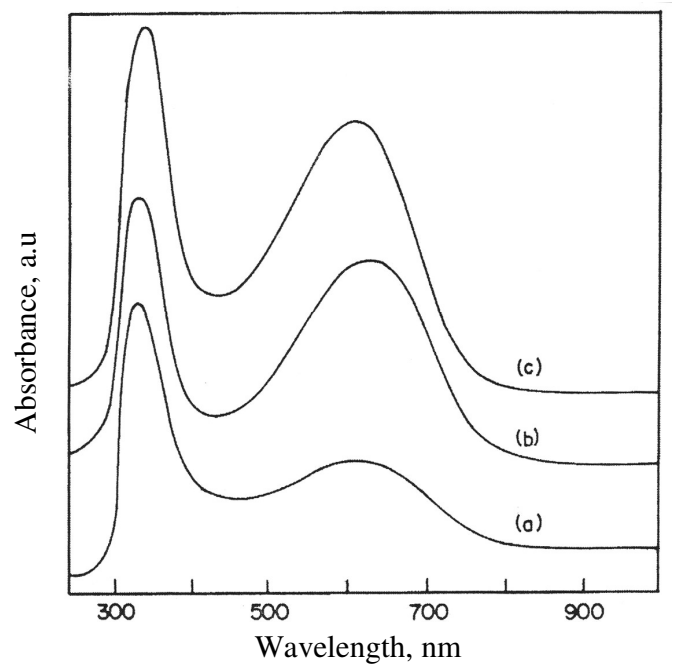

Figure 3. UV-visible spectra of polyaniline (a), poly(o-toluidine) (b), and poly(o-anisidine) (c) dedoped with dilute ammonia 
Polyaniline is not completely soluble in common organic solvents because of the stiffness of its backbone. The incorporation of polar functional group or alkyl chain in the polymer backbone is become soluble in water or organic solvents. Since one ortho position is blocked in 2-substituted aniline, a lower content of ortho couplings can be expected to lead to a more regular head to tail polymer structure and thereby to higher polymerization yields. However, the conductivity of the alkyl ring substituted polymers is lower than those of the parent by two orders of magnitude. It has been reported that $o$ - toludine and $o$-anisidine are more easily oxidized than the unsubstituted aniline. The anodic peak potential for the oxidation of aniline is found to be $0.8 \mathrm{~V} v s$. SCE where as the oxidation peak potential of 2- ethylaniline is found at $0.41 \mathrm{~V}$ vs. $\mathrm{SCE}^{18}$. Based on the above fact we have compared the chemical oxidative polymerization of aniline and substituted anilines within clay galleries.

\section{FI-IR studies}

FT-IR spectra of synthesized PANI-MMT nanocomposites together with those of pristine MMT and pure PANI prepared by conventional chemical oxidative polymerization was shown in Figure 4 . Presence of conductive form of PANI in the clay was confirmed by FT-IR studies. The bands at 1600 and $1560 \mathrm{~cm}^{-1}$ consist of benzenoid and quininoid form of polyaniline backbone and also these bands implies that the charge neutralization with the counter ion present in the polyaniline chain. The peaks at 1305 and $1245 \mathrm{~cm}^{-1}$ are associated with the $\mathrm{C}-\mathrm{N}$ stretching mode ${ }^{19,20}$. The strong peak at $1041 \mathrm{~cm}^{-1}$ and the peaks at 912 and $840 \mathrm{~cm}^{-1}$ are the characteristic vibrations of MMT. In the higher frequency side a peak at $3250 \mathrm{~cm}^{-1}$ is assigned for the N-H stretching vibrations (Figure 4). In the case of poly( $o$-anisidine) and poly (o-toludine) additional peaks were observed in the higher frequency side for the methyl and methoxy group stretching peaks.

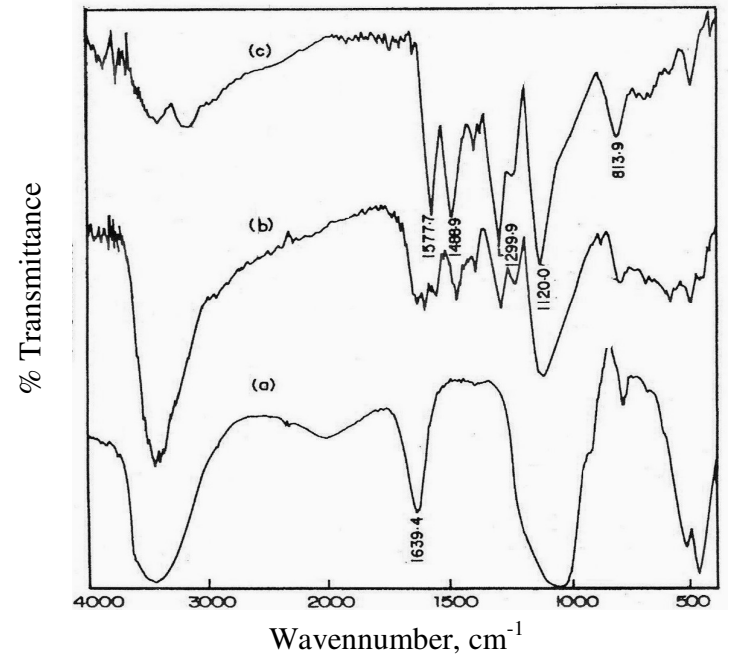

Figure 4. FT-IR spectrum of (a) pristine clay (b) polyaniline clay nanocomposite and (c) chemically synthesized polyaniline

\section{EPR studies}

A sharp EPR signal was observed for the aniline and substituted anilines are intercalated into the clay gallery, which indicates the presence of unpaired electron on anilinium ion. On the other hand, a strong EPR signal was appeared for the polyaniline and substituted polyaniline intercalated clay nanocomposites. The ' $\mathrm{g}$ ' values are close to 2.005 and $\Delta \mathrm{H}_{\mathrm{pp}}$ values are close to 900 Gauss. A similar observation was noted for the in-situ and ex-situ 
polyaniline clay nanocomposites ${ }^{9}$. It is concluded that the strong signal is due to the free charge carrier present in polymer backbone in the confined galleries.

\section{Electrochemical studies}

Electrochemical behavior of polyaniline-MMT synthesized by mechanochemical method has been tested using cyclic voltammetry studies. (Figure 5) shows the cyclic voltammetric behavior of polyaniline-MMT, poly (o-toludine) - MMT and poly (o-anisidine) in $1.0 \mathrm{M}$ $\mathrm{H}_{2} \mathrm{SO}_{4}$ medium. Two set of redox wave was observed for the polyaniline (emeraldine salt form) synthesized by the conventional method in acid medium. A shoulder peak was observed in between the set of redox peak centered at $0.4 \mathrm{~V} v s$. $\mathrm{Ag}$ wire in the anodic side and a peak at $0.3 \mathrm{~V} v s$. Ag wire indicate the quinone formation during polymerization. The first peak is due to the benzenoid form of polyaniline and a redox pair at $0.65 \mathrm{~V}$ and $0.5 \mathrm{~V} v s$. Ag wire for the quninoid form of polyaniline backbone. The redox behavior is as similar as reported results ${ }^{16}$. The redox pairs were not clearly observed in the case of polyaniline intercalated clay nanocomposites. A similar electrochemical response was observed for the poly (o-toludine) clay nanocomposite under the identical experimental condition. However, in the case of poly (o-anisidine)-clay nanocomposite two sets of peaks were observed. Electrochemical polymerization of aniline within clay lattices was reported in the literature and the CV curves are similar in characteristic of mechanochemical grinding method ${ }^{20}$.
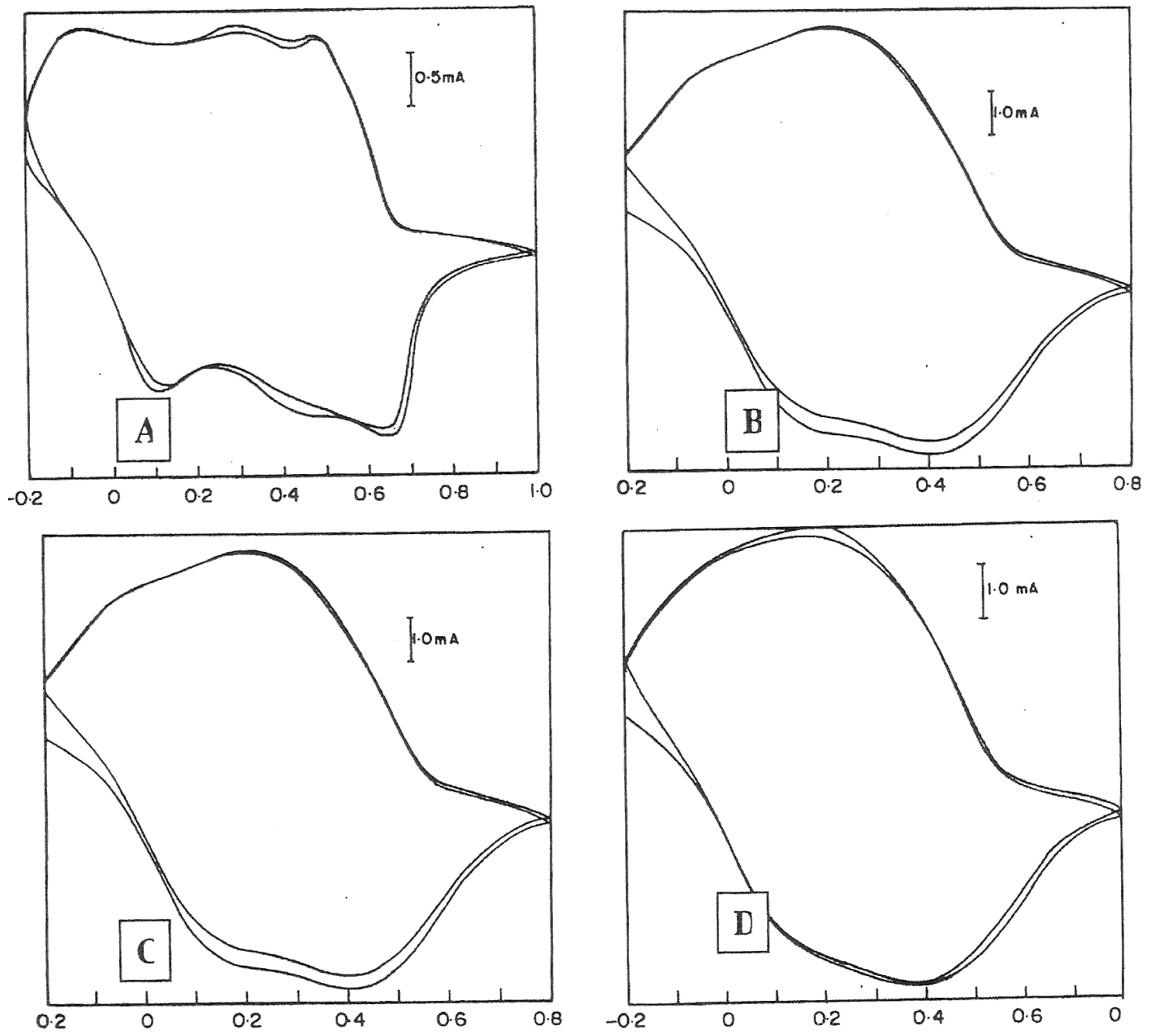

Figure 5. Cyclic voltammogram of (A) pure polyaniline, (B) poly(o-toluidine)-clay nanocomposite, (C) poly(o-anisidine)-clay nanocomposite and (D) polyaniline-clay nanocomposite in $1.0 \mathrm{M} \mathrm{H}_{2} \mathrm{SO}_{4}$ medium with scan rate of $100 \mathrm{mV} / \mathrm{s}$ 


\section{Conclusion}

A detailed investigation has been carried out on the synthesis of various substituted polyaniline/clay nanocomposites by mechanochemical method. From the UV-visible spectral studies, it is concluded that the maximum exchange of aniline ion was achieved by this method and the rate of polymerization of aniline and its derivatives could be controlled in sequential manner. The EPR studies indicate the charge carrier present in the polymer chain is due to the diamagnetic charge carrier. These results reveal that the proposed method is a simple way of production of polyaniline-clay nanocomposites for various applications. Further studies are in progress to characterize the polymerization products using SEM, NMR and mass spectroscopy techniques.

\section{References}

1. Li D, Kaner R B and J Cech, J Am Chem Soc., 2006, 128, 968.

2. Malinauskas A, Polymer., 2001, 42, 3957.

3. Huang J, Shabnam V, Weiller B H and Kaner R B, Chem Eur J., 2004, 10, 1314-1319.

4. Yeh J M, Liou S J, Lai C Y, Wu P C and Tasi T Y, Chem Mater, 2001, 13, 1131.

5. $\quad$ Lu J and Zhao X P, J Mater Res., 2000, 17, 1513-1519.

6. Jing C, Chan L, Shi Y and Jin X, Eur Polym J., 2005, 41(10), 2388.

7. Eckle M and Decher G, Nano Lett., 2001, 1, 45.

8. Lee T W, Park O O, Yoon J Y and Kim J J, Adv Mater, 2001, 13, 211.

9. do Nascimento G M, Constantino V R L and Temperini M L A, Macromolecules, 35, 7535.

10. Yoshimoto S, Ohashi F, Ohnishi Y and Nonami T, Synth Met., 2004, 145, 265-270.

11. Yoshimoto S, Ohashi F, Ohnishi Y and Nonami T, Chem Commun., 2004, 1924.

12. Yoshimoto S, Ohashi F and Kameyama T, J Polym Sci Part B., 2005, 43, 2705.

13. Huang J, Moore J A, Acquaya J H and Kaner R B, Macromolecules, 2005, 38, 317.

14. MacDiarmid A G and Epstein A J, Faraday Discuss Chem., 1989, 88, 317.

15. Ram M K, Carrara S, Paddeu S, Maccion E and Nicolini C, Langmuir, 1997, 13, 2760.

16. Wei Y, Focke W W, Wnek G E, Ray A and MacDiarmaid A G, J Phys Chem., 1989, 94, 495.

17. Wu Q, Xue Z, Qi Z and Wang F, Polymer, 2000, 41, 2029.

18. Leclerc M, Guay J and Dai L H, Macromolecules, 1989, 22, 649.

19. Zheng W, Angelopoulos M, Epstein A J and MacDiarmaid A G, Macromolecules, 1997, 30, 2953.

20 Rasika Dias H V, Wang X, Gamini Rajapakse R M and Elsenbaumer R L, Chem Commun., 2006, 976. 


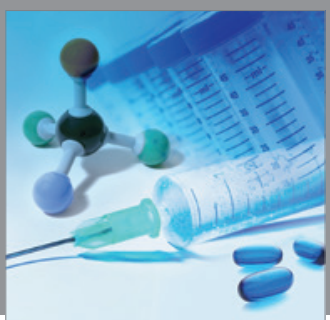

International Journal of

Medicinal Chemistry

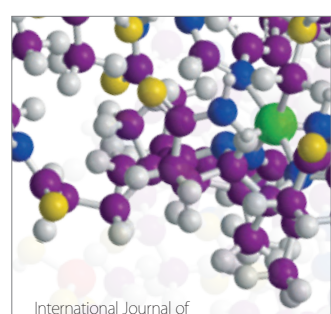

Carbohydrate Chemistry

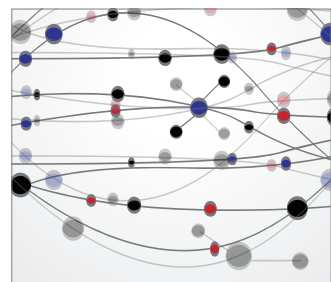

The Scientific World Journal
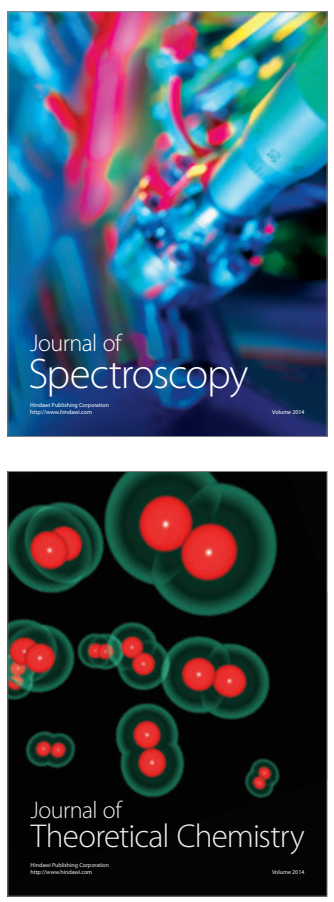
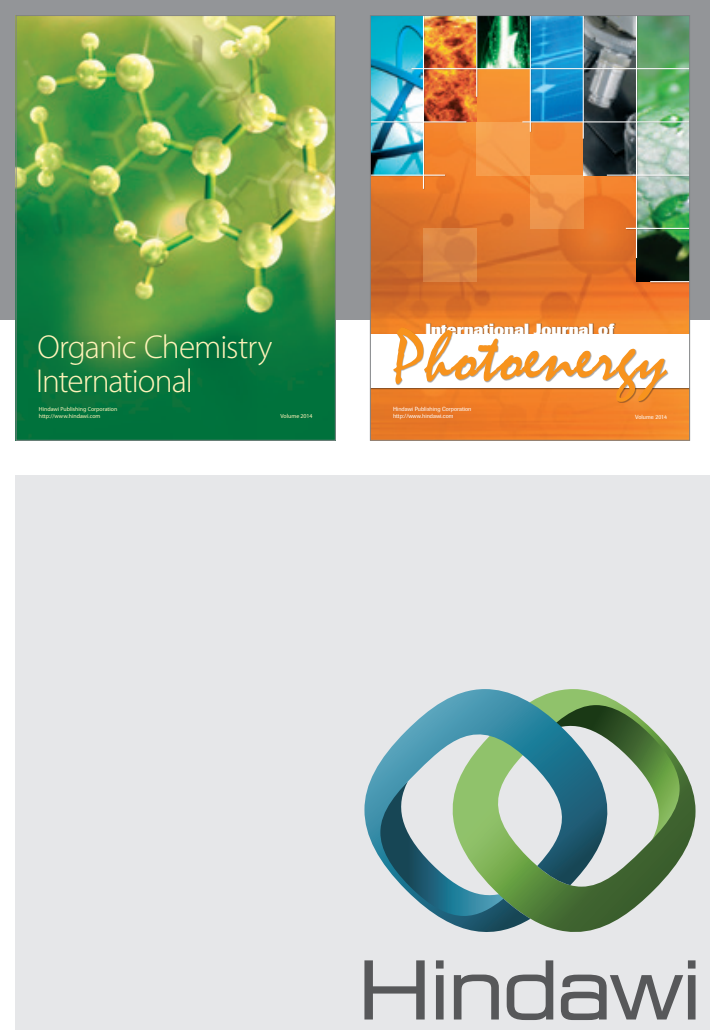

Submit your manuscripts at

http://www.hindawi.com
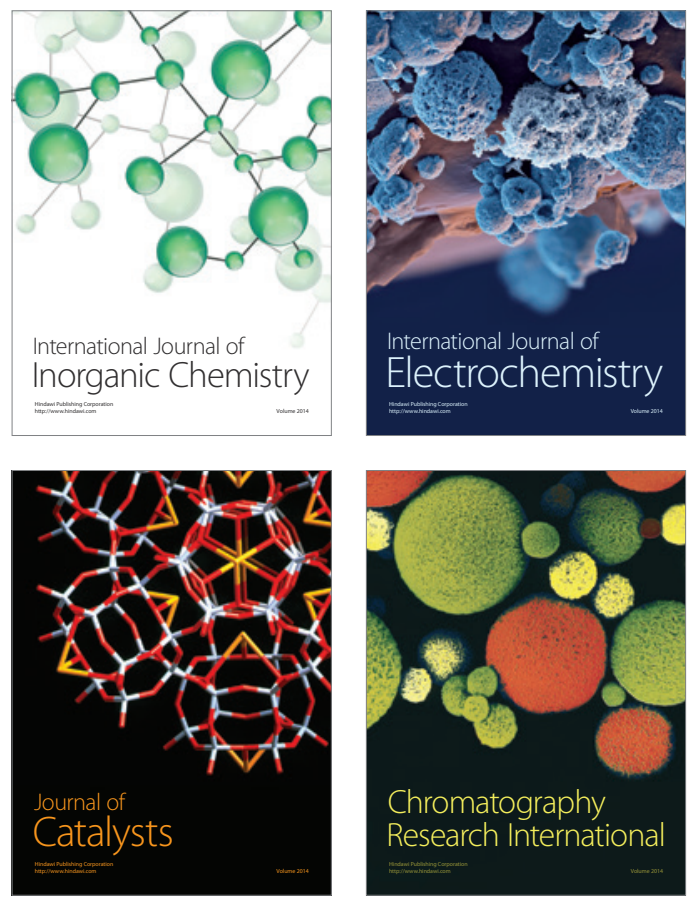
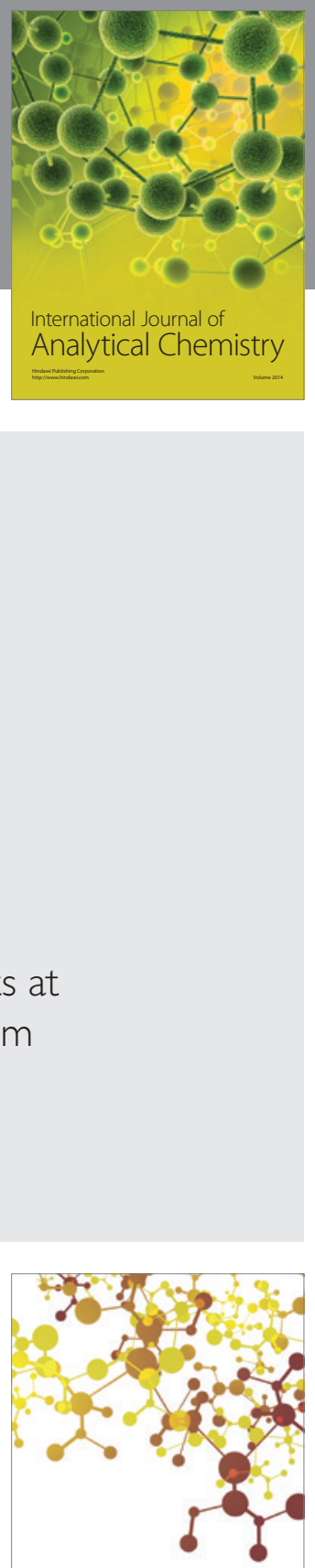

Journal of

Applied Chemistry
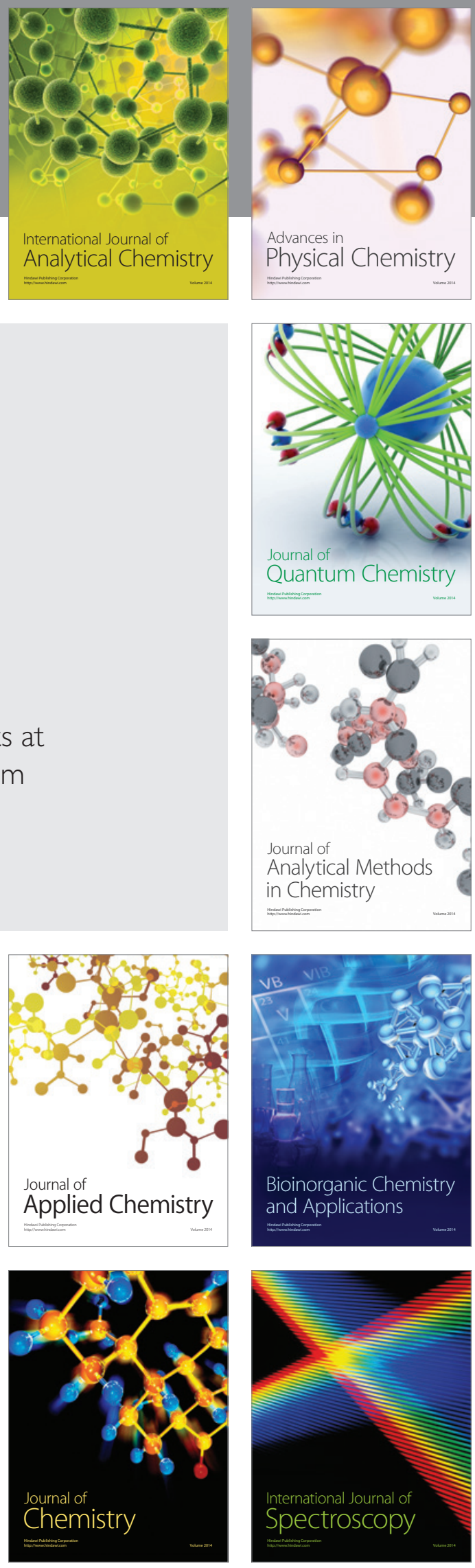